\title{
Experimental investigation on straight and u-bend double tube heat exchanger with active and passive enhancement methods
}

\author{
Rafal Andrzejczyk ${ }^{1, *}$, Tomasz Muszynski ${ }^{1}$, and Przemystaw Kozak ${ }^{1}$ \\ ${ }^{1}$ Gdansk University of Technology, Faculty of Mechanical Engineering, Narutowicza 11/12, 80-233 Gdansk, Poland
}

\begin{abstract}
Authors in this work want to demonstrate the possibility to increase the heat transfer efficiency by using simple wire coil inserts to create turbulent flow in the boundary layer as well as air blowing into the annulus of the pipe. In the study, Wilson plot approach was applied in order to estimate heat transfer coefficients for all heat exchanger (HX) configurations. The study focuses on experimental values of heat transfer coefficient (HTC) and pressure drops. The primary objectives of the work are to: I. Provide an experimental comprehensive database for HTC and pressure drops; II. Analysis effect of different flow conditions e.g.. water mass flow rate, the void fraction on heat transfer and hydraulic performance of tested elements. III. Compare influences of both passive and active methods at the efficiency of simple heat exchangers constructions; IV. Validation experimental results with selected experimental models from the open literature.
\end{abstract}

\section{Introduction}

In recent years, investigations aimed at increasing heat transfer efficiency are of primary importance $[1,2]$. Reducing the energy requirement of energy-intensive systems and also maximization of energy utilization are common subjects of research [3]. For this reason, numerical and experimental studies are conducted in order to create more efficient heat exchangers for thermal energy recovery and storage systems $[4,5]$. In spite of strong progress in various fields of mechanical and materials engineering, simple constructions, such as pipe in pipe, U-type or coil heat exchangers are still very popular. The growing, negative industry impact on environment strongly accelerates the search for new solutions in the field of heat transfer engineering [6]. They are many papers in open literature focuses on heat transfer enhancement techniques in plain heat exchangers constructions. Those techniques as generally divided into passives and active techniques. In passive techniques, there is no required external power. Sheikholeslami et al. [7] presented comprehensive literature review of passive techniques, such as various turbulators (coiled tubes, extended surfaces (fin, winglet),rough surfaces(corrugated tube, rib) and swirl flow devices such as twisted tape, conical ring, snail entry turbulator, vortex rings, coiled wire). They noted that wire coils turbulator provide the best performance increase while maintaining reasonable increase of pressure drop. They also concluded that passive techniques are more popular as heat transfer techniques because of the simple manufacturing process and a possibility to employed to existing heat exchanger construction. Moosavi et al. [8] experimentally tested the possibility to optimize heat transfer and pressure drop characteristics via air bubble injection inside a shell and coiled tube heat exchanger. In the paper, it was emphasized that the air flow rate and injection side play a key role in the possibility to enhance heat transfer in shell coil heat exchanger. Authors noted that the amount of augmentation and curves behavior was completely different when airflow was injected into the shell side and coil side of the heat exchanger.

It should be noted that in all types of heat exchangers heat and fluid flow can be complicated and difficult to predict by means of literature correlations [9], especially in two-phase flow conditions [10-12]. What is more important not many studies concerned at augmentation of heat transfer in case of U-bend double pipe heat exchanger (XH) However latest reports showed the advantage of wire coil turbulators and air bubble injections compare to others heat transfer enhancement techniques. Authors in this study were concentrated on the possibility to combine active and passive techniques to increase the heat performance of plain heat exchangers constructions.

\section{Experimental setup}

In this study four configurations of heat exchangers (HXs) have been used: straight double tube HX, straight double tube HX with helicoidal turbulization (SDTHXT), U-bend double tube HX, U-bend double tube HX with helicoidal turbulization (UBDTHXT). Also experimentally test were done in two-phase flow

\footnotetext{
*Corresponding author: rafal.andrzejczyk@pg.edu.pl
} 
regime (air-water mixture) for all heat exchangers configurations. The heat exchangers were made of copper pipes with the following diameters: $d=10 \mathrm{~mm}$, $\mathrm{D}=18 \mathrm{~mm}$ and wall thickness $1 \mathrm{~mm}$. The total length of the exchanger, in each configuration, was constant and was $430 \mathrm{~mm}$. The helical turbulent element is made of brass wire with a diameter of $2.4 \mathrm{~mm}$ and a pitch of 11 $\mathrm{mm}$. What is more, turbulator was located in the jacket of the heat exchanger. Construction of experimental setup (see Fig.1) provides energy balance in water-water configuration The water inlet and outlet temperature were measures by K-type thermocouples in the first class of accuracy. All thermocouples were connected to the CHY510 meter made in the ITS-90 standard. Pressure difference was measured only at the shell side by PELTRON pressure transducer. The volume flow of water was measured on the shell side of the heat exchanger with a ROL 16 rotameter in class 2.5 and on the inner tube side with a Meterc water meter (T30/90). The volume flow of air was measured with ROL 06 rotameter in class 2.5 .

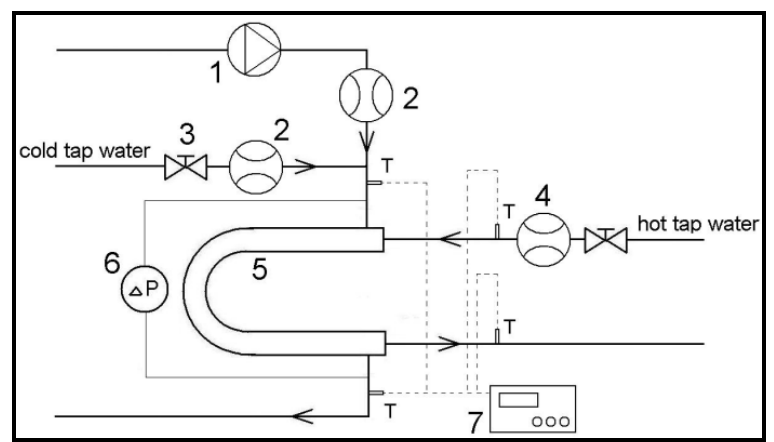

Fig. 1. Experimental setup: 1- compressor, 2 -rotameter, 3 valve, 4- water flow meter, 5- experimental module, 6pressure drop transducer, 7- data acquisition.

Table 1. Uncertainties of selected parameters.

\begin{tabular}{|l|l|l|}
\hline Parameter & $\begin{array}{l}\text { Measuring } \\
\text { range }\end{array}$ & Systematic error \\
\hline $\mathrm{T}\left[{ }^{\circ} \mathrm{C}\right]$ & $10-60$ & Max. error $=+/-2,8 \mathrm{~K}$ \\
\hline $\mathrm{m}[\mathrm{kg} / \mathrm{s}]$ & $\begin{array}{l}0,000056- \\
0,094\end{array}$ & Maximum error $=2,5 \%$ \\
\hline$\Delta \mathrm{P}[\mathrm{kPa}]$ & $0-200$ & Maximum error $=0,5 \mathrm{kPa}$ \\
\hline $\mathrm{Pel}_{\mathrm{el}}[\mathrm{W}]$ & $100-3000 \mathrm{~W}$ & Maximum error $= \pm 5 \%$ \\
\hline
\end{tabular}

To supply resistance heater M10-522-10 250/4 autotransformer was used and Bemco $6907 \mathrm{C}$ wattmeter to measure the actual electrical power of the heater. At table 1 the uncertainties of selected parameters were presented. To estimate heat loss to ambient the infrared photos( Flir E6) of insulation were used. Each time during experiments whole of tested heat exchanger was covered with $10 \mathrm{~mm}$ of polyurethane insulation. Results of calculations shown that heat losses were not larger than $1 \%$, so it was neglected in calculations procedure.

\section{Experimental procedure}

The heat flux in water-water configuration was calculated from energy balance. There were used followed equations:

$$
\begin{aligned}
& \dot{\mathrm{Q}}_{\mathrm{h}}=\dot{\mathrm{m}}_{\mathrm{h}} \cdot \mathrm{c}_{\mathrm{p}} \cdot\left(\mathrm{T}_{\mathrm{h}, \text { in }}-\mathrm{T}_{\mathrm{h}, \text { out }}\right) \\
& \dot{\mathrm{Q}}_{\mathrm{c}}=\dot{\mathrm{m}}_{\mathrm{c}} \cdot \mathrm{c}_{\mathrm{p}} \cdot\left(\mathrm{T}_{\mathrm{c}, \text { out }}-\mathrm{T}_{\mathrm{c} \text {,in }}\right)
\end{aligned}
$$

A number of transfer units was calculated from the formula:

$$
\mathrm{NTU}=\frac{\mathrm{U} \cdot \mathrm{A}}{\mathrm{C}_{\min }}
$$

where the minimum value of the heat capacity was obtained from the next dependence:

$$
\mathrm{C}_{\min }=\mathrm{f}\left(\mathrm{C}_{\mathrm{h}}, \mathrm{C}_{\mathrm{c}}\right)
$$

The overall heat transfer coefficient $U$ was calculated as below:

$$
\mathrm{U}=\frac{\dot{\mathrm{Q}}_{\mathrm{av}}}{\left(\Delta T_{\mathrm{log}} \cdot A\right)}
$$

where: $\dot{Q}_{a v}=\frac{\dot{Q}_{h}+\dot{Q}_{c}}{2}$

Heat transfer effectiveness $\varepsilon[-]$ was calculated from correlations 6-9:

$$
\begin{aligned}
& \varepsilon=\frac{\dot{Q}_{a v}}{\dot{Q}_{\max }} \\
& \dot{Q}_{\max }=C_{\min } \cdot \Delta T_{\max } \\
& \Delta T_{\max }=T_{c, \text { wlot }}-T_{z, \text { wlot }} \\
& \dot{Q}=\dot{Q}_{c}=\dot{Q}_{h}
\end{aligned}
$$

where $\dot{Q}_{\max }[\mathrm{W}]$ is a maximum heat flux that can be received in the tested heat exchanger. At the shell side the Reynolds number at single phase regime was calculated as the mass flow rate through equivalent diameter:

$$
\operatorname{Re}=\frac{G_{s h} \cdot D_{e}}{\mu_{L}}
$$

In case of two-phase flow regime, the liquid Reynolds number was used. This number was calculated as follows:

$$
\operatorname{Re}_{L}=\frac{4 \cdot \dot{m}_{w}}{\pi \cdot \sqrt{1-\varphi} \cdot \mu_{L} \cdot D}
$$


To the calculation of void fraction Chisholm correlation was used [13]:

$$
\varphi=\left[1+\left(\frac{V_{G}}{V_{L}}\right) \cdot\left(\frac{1-x}{x}\right) \cdot \frac{\rho_{G}}{\rho_{L}}\right]^{-1}
$$

Equivalent diameter depends on the volume of the annulus divided by heat exchanger length and circumference.

$$
D e=\frac{4 \cdot V_{s h}}{\pi \cdot D \cdot L}
$$

The volume available for the flow of fluid in the annulus, $\mathrm{V}_{\text {sh }}$ can be calculated knowing geometrical dimensions of the heat exchanger.

$$
V_{s h}=\frac{\pi}{4} D^{2} L-\left(\frac{\pi}{4} d^{2} L+\frac{\pi}{4} d_{c}^{2} L\right)
$$

The measured pressure drop is the sum of friction pressure drop, expansion and contraction losses due to the headers at both ends of the test section. To better compare experimental results for different heat exchanger configurations with different heat transfer enhancement techniques (passive and active) also the performance factor was calculated. Authors were also used similar calculation methodology in their previous study [14]:

$$
P F=\frac{\frac{N u}{N u_{R}}}{\left(\frac{f}{f_{R}}\right)^{0,33}}
$$

Heat transfer coefficient of shell fluid was calculated based on Wilsons plot method [15] and then the Nusselt number at the shell side was also calculated.

$$
N u=\frac{\alpha_{s h} \cdot D_{e}}{\lambda}
$$

It was assumed Nusselt number for straight double $\mathrm{HX}$ as a reference value. The friction factor was calculated as below [7]:

$$
f=\frac{\Delta P}{\left(\frac{\rho_{L} \cdot w^{2}}{2}\right) \cdot\left(\frac{L}{D_{e}}\right)}
$$

\section{Results and discussion}

As can be seen in figures: 2,3 pressure drops are significantly larger for heat exchangers with helicoidal turbulator. It should be also noted that in two-phase flow regime pressure drops were always larger than in single phase.

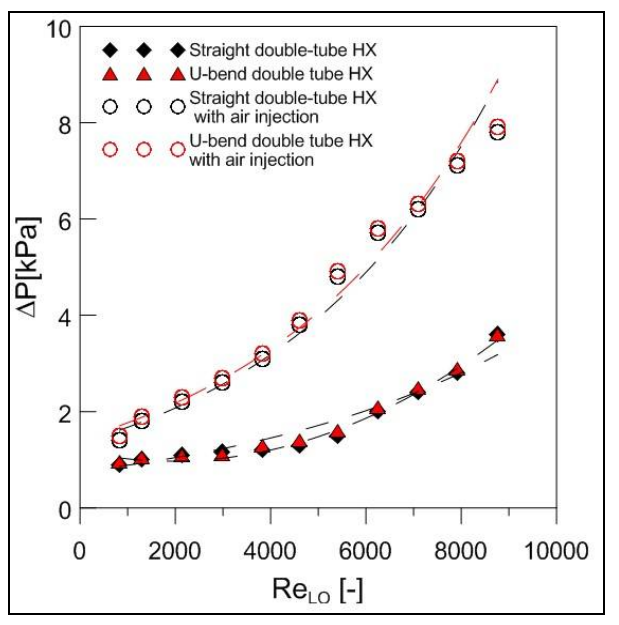

Fig. 2. Hydraulic characteristic at shell side for SDTHX and UBDTHX in single and two-phase flow regimes.

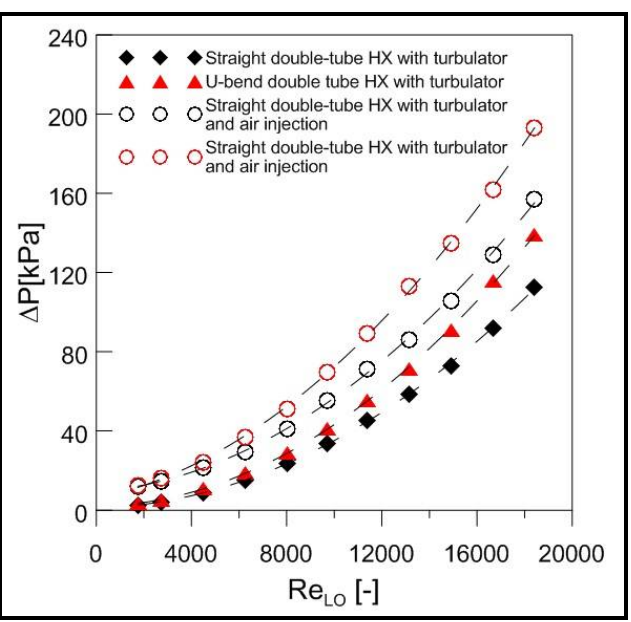

Fig. 3. Hydraulic characteristic at shell side for SDTHXT and UBDTHXT in single and two-phase flow regimes.

In case of single phase flow regime, (see Fig.4) the U-bend double heat exchanger (U-BDTHX) has larger values of the Nusselt number at a whole range of Reynolds numbers. However, the difference is no larger than $50 \%$. Outcomes were compared with very wellknown Dittus-Boelter correlation. It should be noted that experimental results for straight double tube HX (SDTHX) have a good fit with that correlation. The situation is quite opposite in case of those heat exchangers working at two-phase flow conditions (airwater mixture), see Fig.5. This time SDTHX has larger values of Nusselt numbers at a whole range of liquid Reynolds numbers (the same water mass flow rate as in single phase regime). The Nusselt numbers are almost two-times larger compared to the single phase in case of SDTHX and more than $50 \%$ larger in case of UBDTHX. The experimental results for the two-phase flow regime were compared with Kim et al. correlations [16]. Both calculations methodology provided results with fairly good accuracy. However, the literature correlations overestimate Nuselt numbers in case of UBDTHX and underestimate Nusselts number for 
SDTHX. It should be also emphasized that HXs working at two-phase flow-regime are characterized larger thermal power as well as larger pumping power consumptions Despite the fact that, $\varepsilon$-NTU analysis (Fig.6) shows that all of the designs presented are of similar efficiency. However in two-phase flow regime constructions are characterized by higher NTU values, which ultimately results in a maximum efficiency of $58 \%$ for UBDTHX and $55 \%$ for SDTHX. In case of single phase flow regime, (see Fig.7) the U-bend double heat exchanger with turbulator (U-BDTHXT) has larger values of the Nusselt number at a whole range of Reynolds numbers.

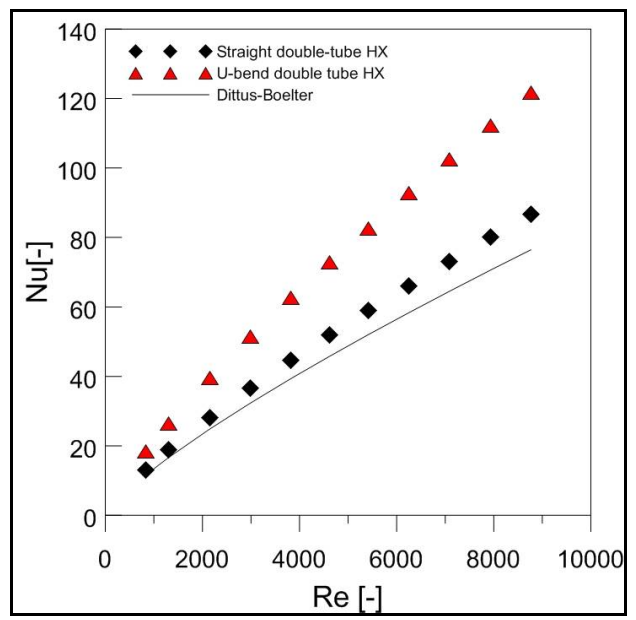

Fig. 4. Nusselt number at shell side for SDTHX and UBDTHX in single phase flow regime.

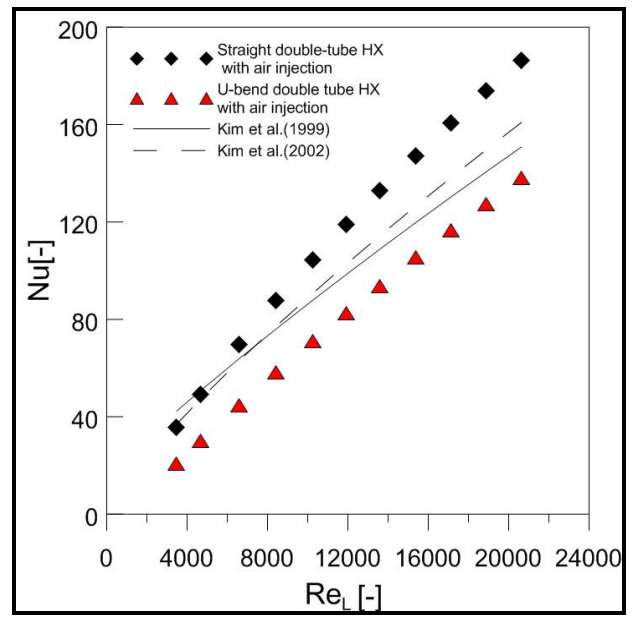

Fig. 5. Nusselt number at shell side for SDTHX and UBDTHX in two-phase flow regime.

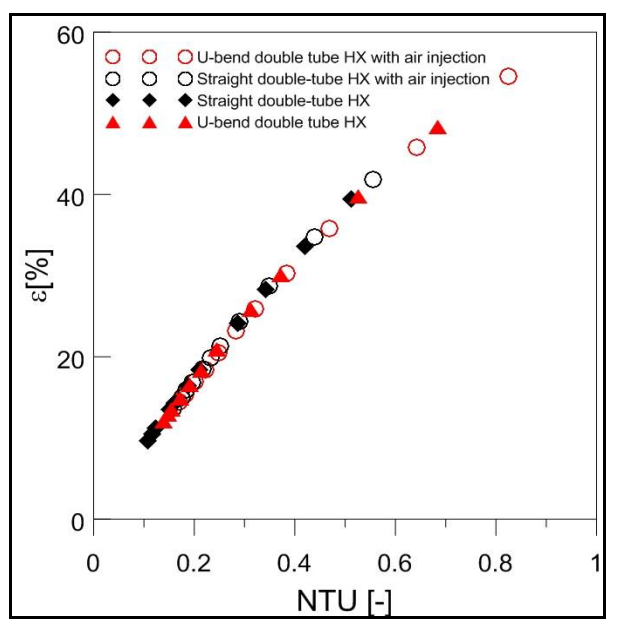

Fig. 6. The dependence of heat transfer efficiency as a function of the NTU for SDTHX and UBDTHX in single and two-phase flow regimes.

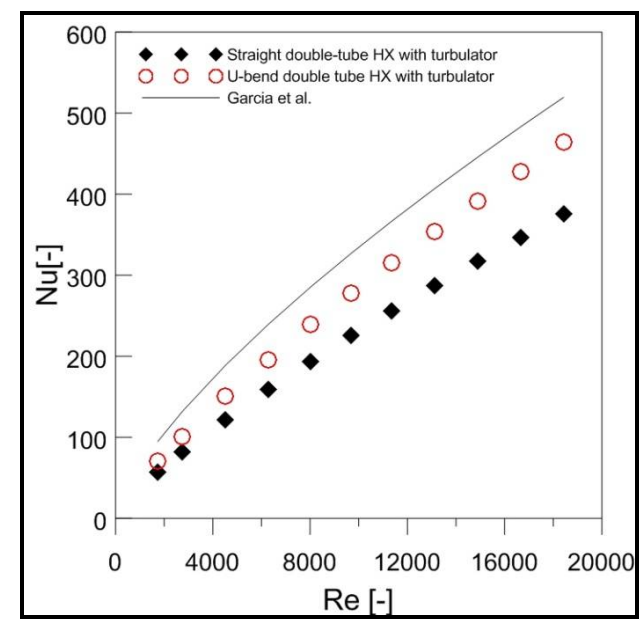

Fig. 7. Nusselt number at shell side for SDTHX and UBDTHX with helicoidal turbulator in single phase flow regime.

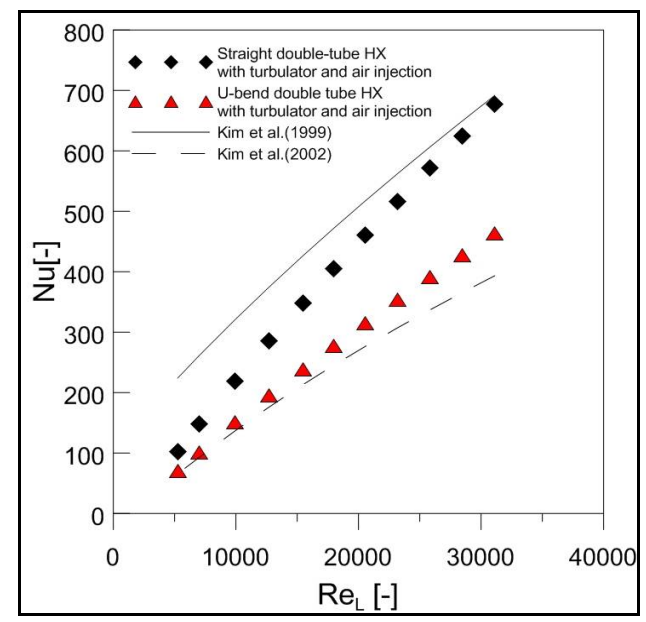

Fig. 8. Nusselt number at shell side for SDTHX and UBDTHX with helicoidal turbulators in two-phase phase flow regime. 


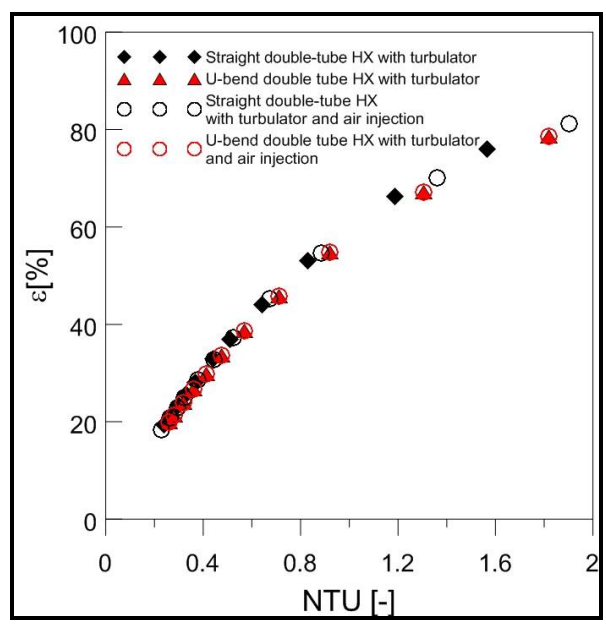

Fig. 9. The dependence of heat transfer efficiency as a function of the NTU for SDTHXT and UBDTHXT in single and twophase flow regimes.

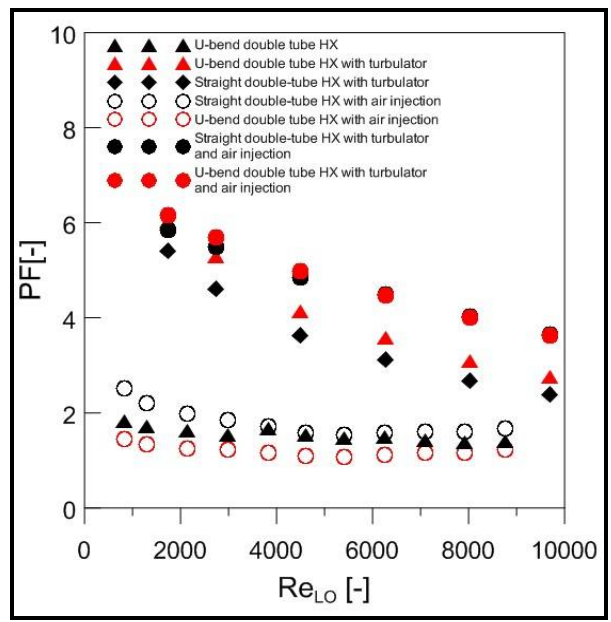

Fig. 10. The dependence of performance factor as a function of $\mathrm{Re}_{\mathrm{LO}}$ for all heat exchangers configurations.

Both HX configuration with helicoidal turbulator are characterized by more than two times larger values of Nusselt Numbers compare to plain constructions. Outcomes of Garcia et al. [17] correlation for heat exchangers with helicoidal turbulators. The correlation quite good predict results for UBDTHXT but it overestimates results for straight $\mathrm{HX}$ with helicoidal turbulator (SDTHXT).Like in the case of plain constructions two-phase flow regime SDTHXT has larger values of Nusselt numbers at a whole range of liquid Reynolds numbers (the same water mass flow rate as in single phase regime). However, the difference in case of U-bend HX construction between results for single-phase and two-phase flow is not significant. The experimental results for the two-phase flow regime were compared with Kim et al. correlations [16]. Kim et al (1999) methodology [16].better predicted experimental results for straight $\mathrm{HX}$ but for U-bend HX Kim et al. (2002) [16] offered better fits to experimental data. Again HXs with helicoidal turbulator working at twophase flow-regime are characterized larger thermal power as well as larger pumping power consumptions. However in two-phase flow regime constructions are characterized by higher NTU values, which ultimately results in a maximum efficiency of $80 \%$ for SDTHXT and $78 \%$ for UBDTHXT. In order to emphasize the impact of the presented modification of flow geometry in the shell side of double tube HXs, the results were compared with reference data for plain construction of double tube heat exchanger. It should be noted that all heat exchangers configurations have better performance than the plain tube in tube heat exchanger.

There was no significant performance difference found between plain U-bend double tube heat exchanger and SDTHX and UBDTHX working on two-phase flow regime ( with air injection). It could be explained by the fact that the air injection increases flow turbulisation and heat transfer but also significantly increase pressure drops. In plain U-bend heat exchanger, there is also heat transfer enhancement mechanism, so-call Dean effect, which slightly increases heat transfer but also doesn't significantly increase pressure drops. This approach could be also used to explain the difference between SDTHXT performance and UBDTHXT. The U-bend heat exchanger with helicoidal turbulator has better performance than the straight heat exchanger with the same turbulator. However, configurations with helicoidal turbulators working in two-phase flow conditions (airwater mixture) had the best performance. It should be emphasized that this combination of active and passive techniques provide larger than $300 \%$ performance in the whole flow regime compare to reference plain heat exchanger configuration( see Fig. 10).

\section{Conclusions}

The article presents passive and active heat transfer enhancement methods in the form of helicoidal turbulator and air bubble injection. Both used heat transfer enhancement techniques provided better heat exchangers performance compare to reference plain double tube heat exchanger. The heat exchangers configurations with helicoidal turbulators working in two-phase flow conditions (air-water mixture) had the best performance. What is also important still such combination of heat transfer enhancement techniques in heat exchangers do not increase significantly relation between heat flux and pumping power. However, it should be noted that for smaller values of Reynolds number $\left(\operatorname{Re}_{\mathrm{LO}}<3000\right)$ it seems that simplest is to use just passive enhancement techniques (e.g. helicoidal turbulator). The experimental results were compared with selected well-known correlation from the open literature. It worth to added that especially in heat exchangers configurations with helicoidal turbulator (single phase flow regime) results of calculations were clearly overestimated compare to experimental data. 


\section{Acknowledgements}

The authors would like to appreciate funding received from the Research Council of Norway under the FRINATEK Project 231529 .

\section{Nomenclature}

A - heat transfer area, $\mathrm{m}^{2}$,

C - thermal capacity, $\mathrm{W} / \mathrm{K}$

$\mathrm{Cp}$ - specific heat, $\mathrm{kJ} /(\mathrm{kgK})$

$\mathrm{D}, \mathrm{d}$ - diameter of the annulus, inner tube, $\mathrm{m}$

$\mathrm{D}_{\mathrm{e}} \quad$ - equivalent diameter, $\mathrm{m}$

f - friction factor,

$\mathrm{G}-$ mass flux, $\mathrm{kg} /\left(\mathrm{m}^{2} \mathrm{~s}\right)$

$\mathrm{L} \quad$ - Length of annulus tube, $\mathrm{m}$

m - mass flow rate, $\mathrm{kg} / \mathrm{s}$

$\mathrm{Nu}$ - Nusselt number

NTU - the number of transfer units

$\dot{\mathrm{Q}}$ - heat flux, W,

Re - Reynolds number

$\mathrm{T}, \Delta \mathrm{T}-$ temperature, temperature difference ${ }^{\circ} \mathrm{C}$,

$\mathrm{V}$ - volumetric flow, $\mathrm{m}^{3} / \mathrm{s}$

$\varepsilon \quad$ - heat transfer effectiveness

$\varphi \quad-$ void fraction

$\mathrm{m}$ - dynamic viscosity, Pas

$\rho \quad-$ density, $\mathrm{kg} / \mathrm{m}^{3}$

\section{Subscripts}

$$
\begin{array}{ll}
\text { a } & \text { - annulus } \\
\text { av } & \text { - average } \\
\text { c } & \text { - cold, coil wire } \\
\text { h } & \text { - hot } \\
\text { G } & - \text { gas } \\
\text { in } & \text { - inlet } \\
\text { L } & - \text { liquid } \\
\text { LO } & \text { - liquid only } \\
\text { max } & \text { - maximum } \\
\text { min } & \text { - minimum } \\
\text { out } & \text { - outlet } \\
\text { R } & \text { - reference }
\end{array}
$$

\section{References}

1. Q. Wang, M. Zeng, T. Ma, X. Du, J. Yang, Appl. Energy 135 (2014)

2. R. Andrzejczyk, T. Muszyński, Arch. Thermodyn. 37 (2016)

3. T. Muszynski, S.M. Koziel, Arch. Thermodyn. 37 (2016)

4. D. Taler, P. Ocłoń, Int. J. Therm. Sci. 84 (2014)

5. T. Muszynski, Appl. Therm. Eng. 115 (2017)

6. P. Olszewski, Appl. Therm. Eng. 81 (2015)

7. M. Sheikholeslami, M. Gorji-Bandpy, D.D. Ganji, Renew. Sustain. Energy Rev. 49 (2015)

8. A. Moosavi, M. Abbasalizadeh, H.S. Dizaji, Exp. Therm. Fluid Sci. 78 (2016)
9. R. Andrzejczyk, T. Muszynski, Appl. Therm. Eng. 121 (2017)

10. T. Muszynski, R. Andrzejczyk, C.A. Dorao, Int. J. Refrig. 82 (2017)

11. T. Muszyński, R. Andrzejczyk, C.A. Dorao, Arch. Thermodyn. 38 (2017)

12. R. Andrzejczyk, T. Muszynski, C.A. Dorao, Exp. Therm. Fluid Sci. 83 (2017)

13. D. Chisholm, Institution of Chemical Engineers (London, 1983)

14. A.A. Rezaei, M. Ziabasharhagh, Heat Transf. Res. 42 (2013)

15 J. Fernandez-Seara, F.J. Uhía, J. Sieres, A. Campo, Appl. Therm. Eng. 27 (2007)

16. S.-M. Kim, I. Mudawar, Int. J. Heat Mass Transf. 58 (2013)

17 J. Garcia, M.P. Porto, R. Revellin, J. Bonjour, L. Machado, Int. J. Refrig. 73 (2017) 